\title{
Giant Orbitoethmoidal Osteoma: When an Open Surgical Approach Is Required
}

\author{
Hussam Abou Al-Shaar, ${ }^{1,2}$ Turki El Arjani, ${ }^{1,2}$ Michael S. Timms, ${ }^{2,3}$ and Faisal Al-Otaibi ${ }^{1,2}$ \\ ${ }^{1}$ Division of Neurological Surgery, Neurosciences Department, King Faisal Specialist Hospital and Research Center, \\ P.O. Box 3354, Riyadh 11211, Saudi Arabia \\ ${ }^{2}$ College of Medicine, Alfaisal University, Riyadh 11533, Saudi Arabia \\ ${ }^{3}$ Department of Otolaryngology, King Faisal Specialist Hospital and Research Center, P.O. Box 3354, Riyadh 11211, Saudi Arabia
}

Correspondence should be addressed to Faisal Al-Otaibi; faisalruwais@gmail.com

Received 26 December 2014; Revised 17 March 2015; Accepted 18 March 2015

Academic Editor: Rong-San Jiang

Copyright (C) 2015 Hussam Abou Al-Shaar et al. This is an open access article distributed under the Creative Commons Attribution License, which permits unrestricted use, distribution, and reproduction in any medium, provided the original work is properly cited.

Giant orbitoethmoidal osteoma in children is considered to be rare. This type of pathology can be associated with significant disfiguring proptosis and limitation of eye movement. Here, we report on a child who presented with a giant orbitoethmoidal osteoma that was removed through an orbitofrontal approach. The cosmetic result was excellent and evident immediately after surgery. A review of the literature complements this report.

\section{Introduction}

Osteomas are uncommon tumors that constitute $1 \%$ of all bone tumors and $11 \%$ of benign bone tumors [1]. Skull base osteomas arising in the ethmoid sinus are extremely rare, especially giant lesions [2-4]. Symptomatic lesions usually present with symptoms related to their anatomical location [3]. A computed tomography (CT) scan is the modality of choice to diagnose these lesions. Asymptomatic ethmoidal osteomas can be managed conservatively with serial radiological images, while symptomatic lesions should be managed surgically [3,4]. Herein, we report on a child with giant orbitoethmoidal osteoma. In addition, a literature review of orbitoethmoidal osteomas is provided, with focus on surgical management options for giant orbitoethmoidal osteomas.

\section{Case Report}

A 16-year-old boy presented with progressive proptosis in the left eye that had first appeared 3 years earlier. He had recently developed limitation of left-eye movement associated with double vision. During physical examination, downward deviation and protrusion of the left eye and limitations of lateral and vertical gaze were evident (Figure 1). No papilledema or optic atrophy was detected on fundoscopic examination. A CT scan of the orbit revealed a hyperdense giant mass occupying the left supraorbital region, frontal sinus, and left ethmoid, with extension to the left nostril. In addition, the radiological feature of severe proptosis in the left eye was seen.

The features of this mass are suggestive of osteoma. The mass was removed through a left fronto-orbital approach. A supraorbital frontal craniotomy was carried out, exposing the osteoma at the supraorbital and the ethmoid regions (Figure 2). The supraorbital rim was involved by the mass. Reconstruction of the supraorbital rim and frontal bone with MEDPOR mesh was performed. The patient had an uneventful postoperative course. The cosmetic effect of the procedure was excellent immediately after surgery (Figure 3 ).

\section{Discussion}

Osteomas are exceedingly rare benign osteogenic tumors [3]. They can arise from any bony structure, with the paranasal sinuses being the most common location. They are most commonly encountered in the frontal sinus, followed by the ethmoidal, maxillary, and sphenoid sinuses, in that order [5]. The prevalence of osteomas is estimated to be $0.43-1 \%$ within the population $[5,6]$. Osteomas larger than $3 \mathrm{~cm}$ in diameter 

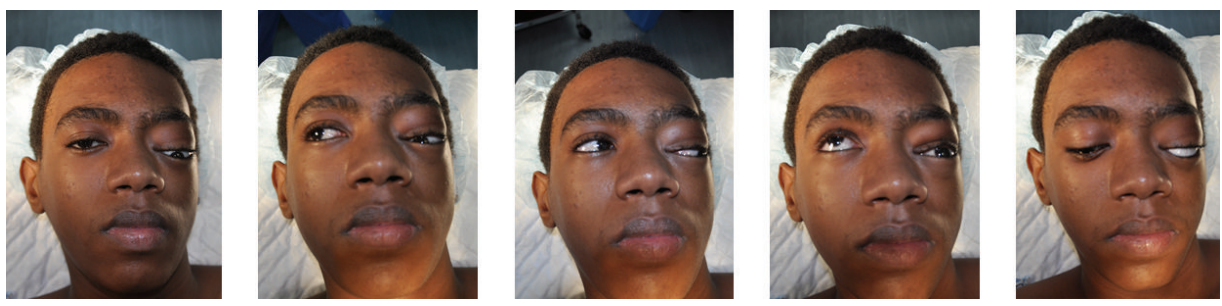

(a)

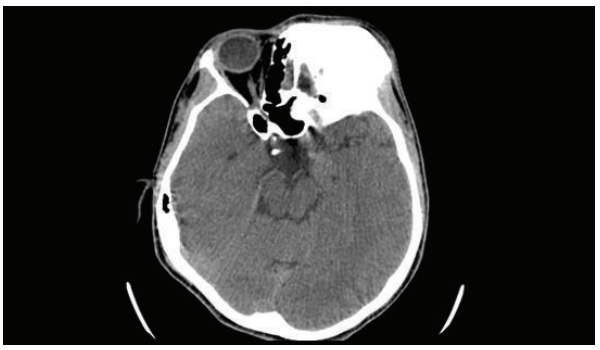

(b)

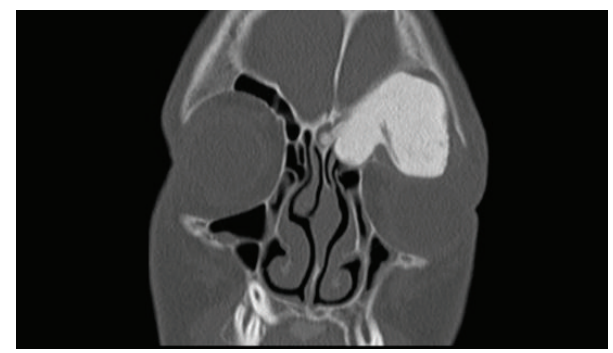

(c)

Figure 1: Patient photo demonstrating the degree of proptosis and limitation of eyemovements (a). Computerized tomography (axial (b) and coronal (c)) depicting giant osteoma feature at the orbitoethemoidal region and the degree of orbital compression.

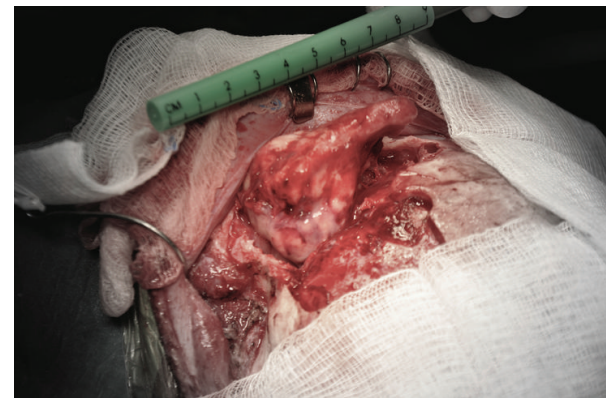

FIGURE 2: Intraoperative photo showing the large osteoma exposed through a fronto-orbital surgical approach.

and weighing more than $110 \mathrm{~g}$ are considered giant tumors [7]. Though most osteomas are sporadic, patients with Gardner's syndrome, an autosomal dominant disease, are at increased risk of developing osteomas alongside other diseases [5].

The etiology of osteomas remains elusive. Three different hypotheses have been described in the literature, identifying possible instigators for osteoma formation $[2,3]$. The infectious theory is based on the presence of bony hyperplasia as a result of chronic infection and inflammation. The embryologic theory revolves around the persistence of embryologic or cartilaginous cell remnants in the junctional zone around the labyrinth of the ethmoidal bone. The traumatic theory describes the origin of osteomas in previous head injury sites, which might explain the slight increase in prevalence among males. A combination of the latter two theories remains the most largely accepted etiological theory.

Most osteoma patients are asymptomatic. It is estimated that around $1 \%$ of osteomas are discovered incidentally on sinus plain X-rays, while only $3 \%$ are detected via CT scans [8]. The close proximity of the orbit to the ethmoid sinus increases the risk of ocular symptoms of giant extending ethmoidal osteomas, as seen in our case. Although rare, proptosis, exophthalmos, diplopia, and other ocular symptoms may occur as a result of orbital displacement by the tumor and can be the first complaints in such patients [3,9]. Surgical intervention is indicated in the presence of symptoms, significant growth, or extension beyond the sinus borders on followup imaging. Orbital and sphenoid sinus osteomas, however, regardless of their size or symptoms, should be resected whenever encountered because of the potential that these progressive, slow-growing tumors can compress the visual pathways and cause blindness [4].

Surgical techniques for the treatment of osteomas remain controversial. The surgical approach should be based on tumor size, tumor location, and the surgeon's preference and experience [3]. Symptomatic orbitoethmoidal osteomas have been managed surgically with open procedures for decades. The osteoplastic flap technique, anterior surgical exposure (craniofacial, transcoronal, and transcutaneous paranasal approaches), external fronto-ethmoidectomy, and lateral rhinotomy have all been described in the literature as possible techniques in the resection of giant osteomas that extend beyond the ethmoid sinus [4, 10-14]. The complications of the open surgical approaches are comparable with those encountered using the endoscopic technique. Recurrent frontal sinusitis, iatrogenic cranial nerve injury, visual disturbances, ptosis, CSF leakage, and postoperative hemorrhage have been reported in the literature with the open surgical techniques $[15,16]$.

With recent technological innovation in the surgical techniques and the introduction of endoscopic surgical interventions, many authors consider endoscopic resection of ethmoidal and orbitoethmoidal osteomas to be the new modality of choice for resecting such lesions $[4,17]$. The minimally invasive endoscopic endonasal approach allows greater, 

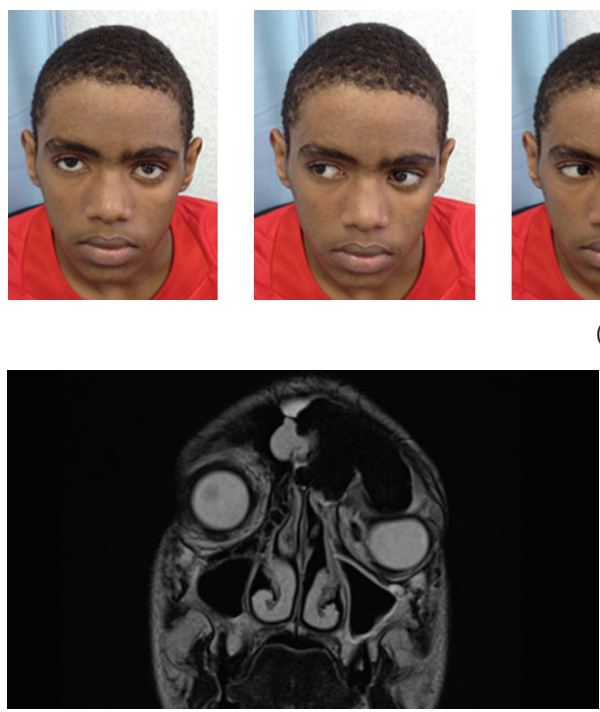

(b)
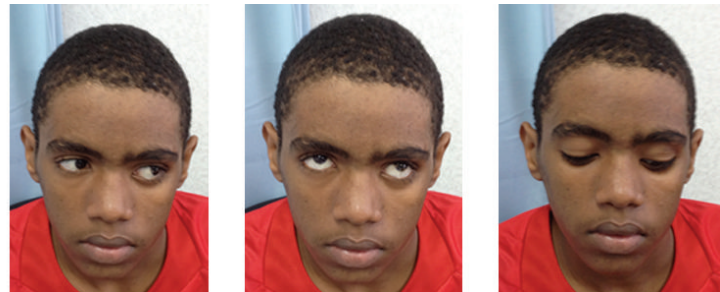

(a)

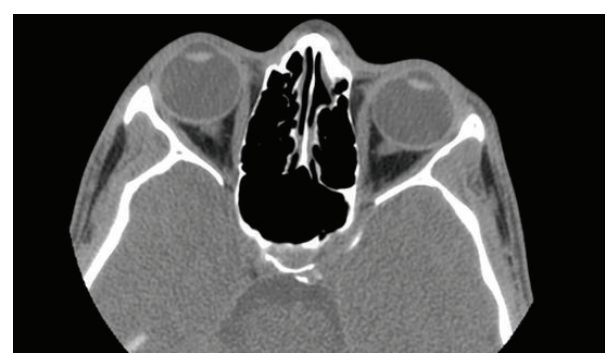

(c)

FIGURE 3: Postoperative patient photo demonstrating the resolution of proptosis and fulleye movements (a). Preoperative coronal MRI orbit showing the degree of compression on the orbit (b). Postoperative CT orbit showing the resolution of proptosis (c).

closer, and more direct visualization of the tumor. Bony reconstruction of the walls, which is not usually indicated in ethmoidal osteomas, remains a limitation of the endoscopic approach [18]. In the presented case, the osteoma is extensive and involves the orbit with lateral extension making an endoscopic approach difficult. In addition, the superior orbital rim is involved, which mandates a reconstruction.

The surgical goal is to achieve complete surgical resection, protect vital structures (cribriform plate, optic nerves, lacrimal apparatus, anterior and posterior ethmoidal arteries, and the trochlea), and achieve favorable aesthetic outcomes [3]. Complete surgical excision can be achieved by en bloc resection of the osteoma whenever possible. Drilling the center of hard and/or giant osteomas to create a central cavity with thinning of the tumor peripheral walls, elevation of the tumor from the adjacent tissue and skull base, and subsequent removal with curette or by cutting should be considered for these lesions $[7,18]$. In the presence of orbital extension, a similar approach can be considered for decompression of the orbit and optimal removal of the tumor [3]. Although extremely uncommon, incomplete resection of the osteoma is associated with increased risk of recurrence (up to $10 \%$ ) $[1,5]$.

Most literatures describing giant orbitoethmoidal osteomas are case reports and small series. Therefore, the superiority of one surgical approach over the other is not yet established. However, in the presence of gigantic lesions with lateral extension beyond the orbital midline, as seen in our case, open surgical approaches are effective and were deemed more desirable.

\section{Conclusion}

Giant orbitoethmoidal osteomas have been managed with open approaches for decades. Only scarce case reports and small series are present in the literature. Our case adds to the growing literature on giant orbitoethmoidal osteomas managed successfully using open surgical approaches. Although the endoscopic endonasal approach demonstrates a safe and effective technique for the surgical management of giant orbitoethmoidal osteomas, the presence of a giant orbitoethmoidal osteoma that extends superolaterally into the orbital and frontal regions beyond the orbital midline might limit the endoscopic approach, and an open procedure offers the optimal surgical approach and orbitofrontal reconstruction.

\section{Consent}

Permission consent was taken from the patient guardian and patient to display his photo in this paper.

\section{Conflict of Interests}

The authors declare that they have no conflict of interests.

\section{References}

[1] A. B. Grayeli, A. Redondo, and O. Sterkers, "Anterior skull base osteoid osteoma: case report," British Journal of Neurosurgery, vol. 12, no. 2, pp. 173-175, 1998.

[2] M. Naraghi and A. Kashfi, "Endonasal endoscopic resection of ethmoido-orbital osteoma compressing the optic nerve," American Journal of Otolaryngology: Head and Neck Medicine and Surgery, vol. 24, no. 6, pp. 408-412, 2003.

[3] Y. Pons, J.-P. Blancal, B. Vérillaud et al., "Ethmoid sinus osteoma: diagnosis and management," Head \& Neck, vol. 35, no. 2, pp. 201-204, 2013.

[4] T. Muderris, S. Bercin, E. Sevil, and M. Kiris, "Endoscopic removal of a giant ethmoid osteoma with orbital extension," Acta Informatica Medica, vol. 20, no. 4, pp. 266-268, 2012. 
[5] F. S. Haddad, G. F. Haddad, and G. Zaatari, "Cranial osteomas: their classification and management. Report on a giant osteoma and review of the literature," Surgical Neurology, vol. 48, no. 2, pp. 143-147, 1997.

[6] P. Koivunen, H. Löppönen, A.-P. Fors, and K. Jokinen, "The growth rate of osteomas of the paranasal sinuses," Clinical Otolaryngology and Allied Sciences, vol. 22, no. 2, pp. 111-114, 1997.

[7] Y. Izci, "Management of the large cranial osteoma: experience with 13 adult patients," Acta Neurochirurgica, vol. 147, no. 11, pp. 1151-1155, 2005.

[8] A. Brunori, S. de Santis, P. Bruni, A. Delitala, R. Giuffre, and F. Chiappetta, "Life threatening intracranial complications of frontal sinus osteomas: report of two cases," Acta Neurochirurgica, vol. 138, no. 12, pp. 1426-1430, 1996.

[9] B. E. Koktekir, K. Ozturk, S. Gedik, H. Guzel, and P. Karabagli, "Giant ethmoido-orbital osteoma presenting with dacryocystitis and metamorphopsia," The Journal of Craniofacial Surgery, vol. 23, no. 5, pp. e390-e392, 2012.

[10] E. Karbassi, A. Arabi Mianroodi, and A. Shamsadini, "Orbital extension of a giant ethmoidal sinus osteoma in a 30-year-old female," Iranian Journal of Otorhinolaryngology, vol. 25, no. 71, pp. 119-122, 2013.

[11] I. Karapantzos, E. T. Detorakis, E. E. Drakonaki, D. L. Ganasouli, V. Danielides, and V. P. Kozobolis, "Ethmoidal osteoma with intraorbital extension: excision through a transcutaneous paranasal incision," Acta Ophthalmologica Scandinavica, vol. 83, no. 3, pp. 392-394, 2005.

[12] I. Yiotakis, A. Eleftheriadou, E. Giotakis, L. Manolopoulos, E. Ferekidou, and D. Kandiloros, "Resection of giant ethmoid osteoma with orbital and skull base extension followed by duraplasty," World Journal of Surgical Oncology, vol. 6, article 110, 2008.

[13] S. B. Pai, K. Harish, M. S. Venkatesh, and D. Jermely, "Ethmoidal osteoid osteoma with orbital and intracranial extension-a case report," BMC Ear, Nose and Throat Disorders, vol. 5, article 2, 2005.

[14] M. W. Marks and M. H. Newman, "Transcoronal removal of an atypical orbitoethmoid osteoma," Plastic and Reconstructive Surgery, vol. 72, no. 6, pp. 874-877, 1983.

[15] L. A. Wei, N. A. Ramey, V. D. Durairaj et al., "Orbital Osteoma: clinical features and management options," Ophthalmic Plastic and Reconstructive Surgery, vol. 30, no. 2, pp. 168-174, 2014.

[16] I. Benatiya Andaloussi, E. Touiza, S. Bhallil et al., "Orbital osteoma: three case reports," Bulletin de la Société Belge d'Ophtalmologie, no. 300, pp. 73-79, 2006.

[17] S. J. F. Gerbrandy, P. Saeed, and W. J. Fokkens, "Endoscopic and trans-fornix removal of a giant orbital-ethmoidal osteoma," Orbit, vol. 26, no. 4, pp. 299-301, 2007.

[18] R. S. Burgos, J. G. Martín-Moro, J. A. Gallo, F. C. Benito, and M. B. García, "Giant osteoma of the ethmoid sinus with orbital extension: craniofacial approach and orbital reconstruction," Acta Otorhinolaryngologica Italica, vol. 33, no. 6, pp. 431-434, 2013. 


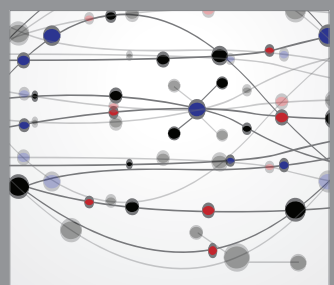

The Scientific World Journal
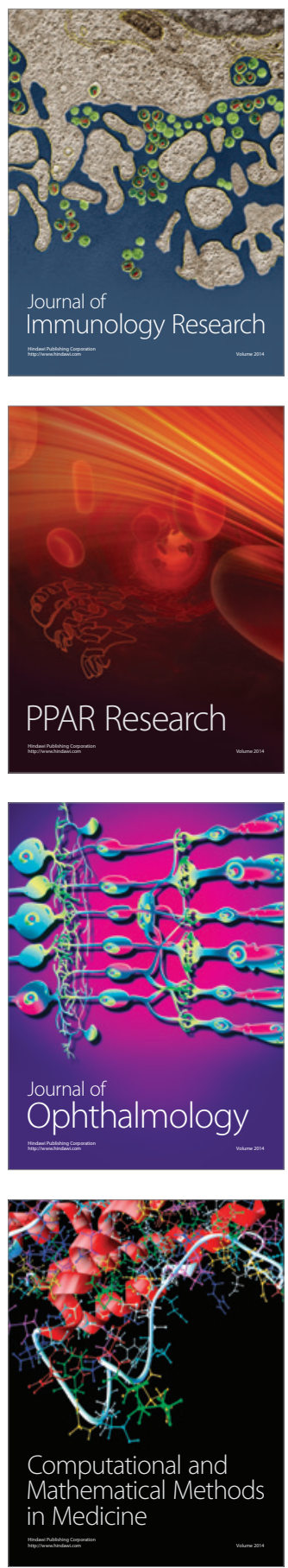

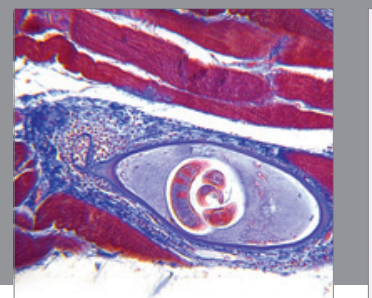

Gastroenterology

Research and Practice
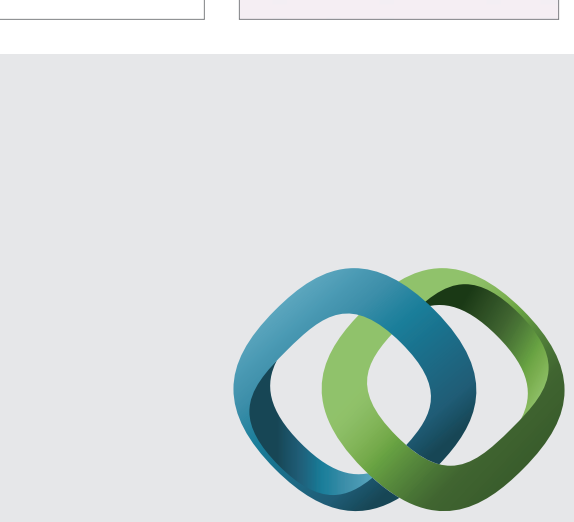

\section{Hindawi}

Submit your manuscripts at

http://www.hindawi.com
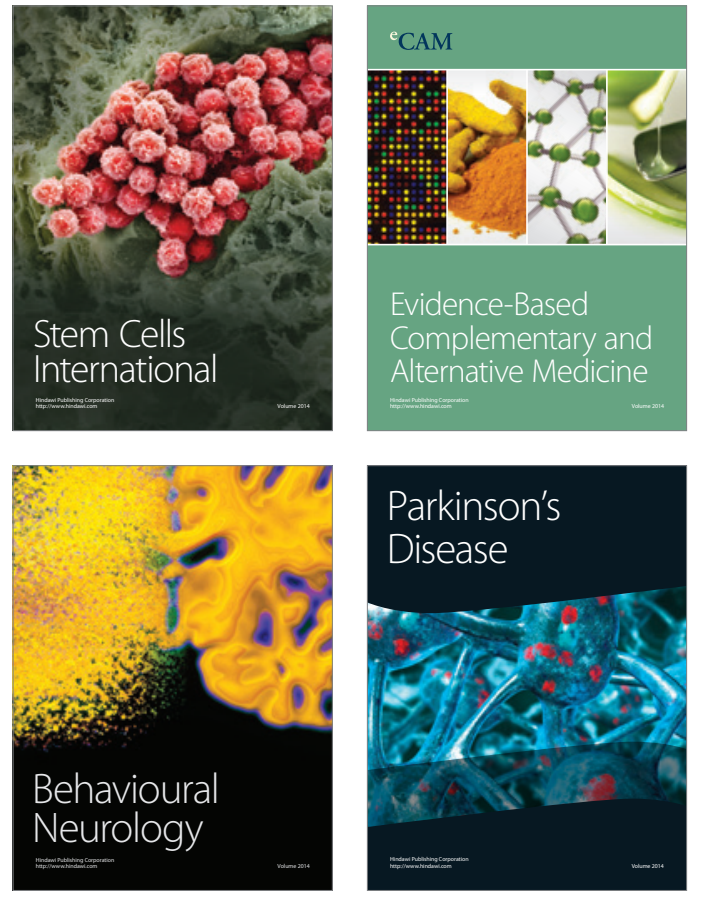
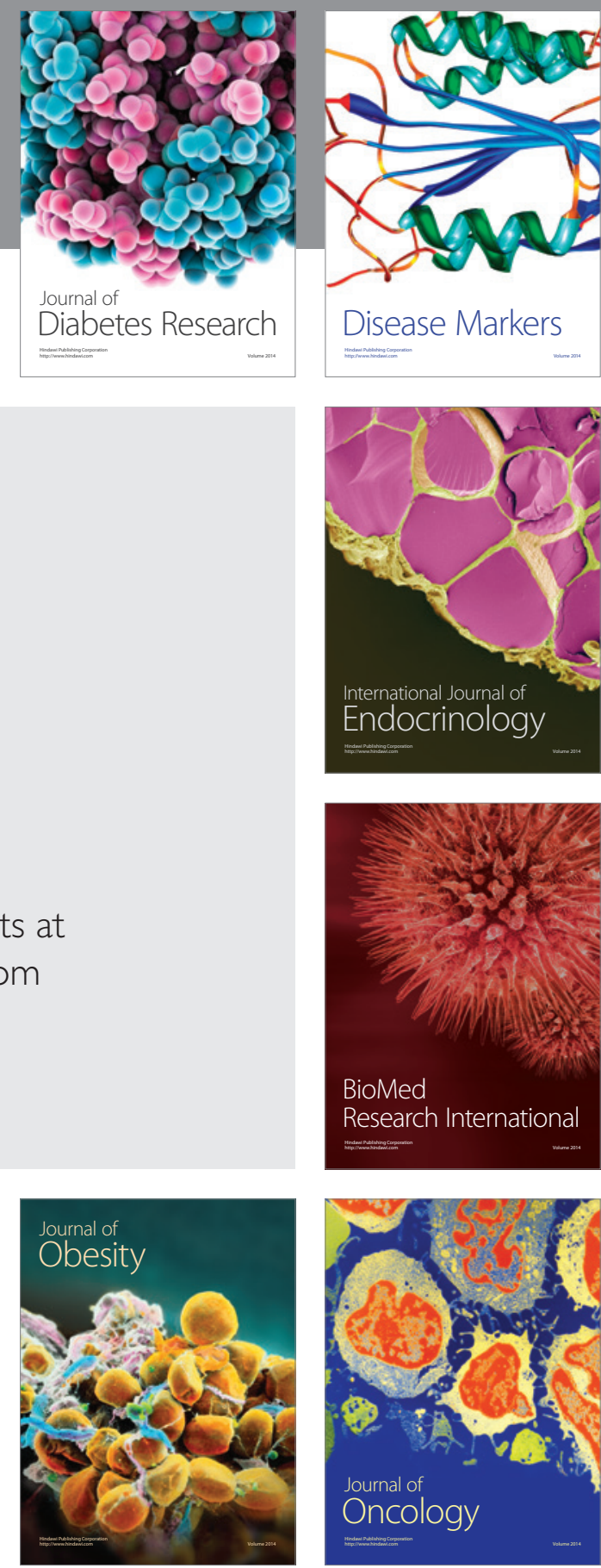

Disease Markers
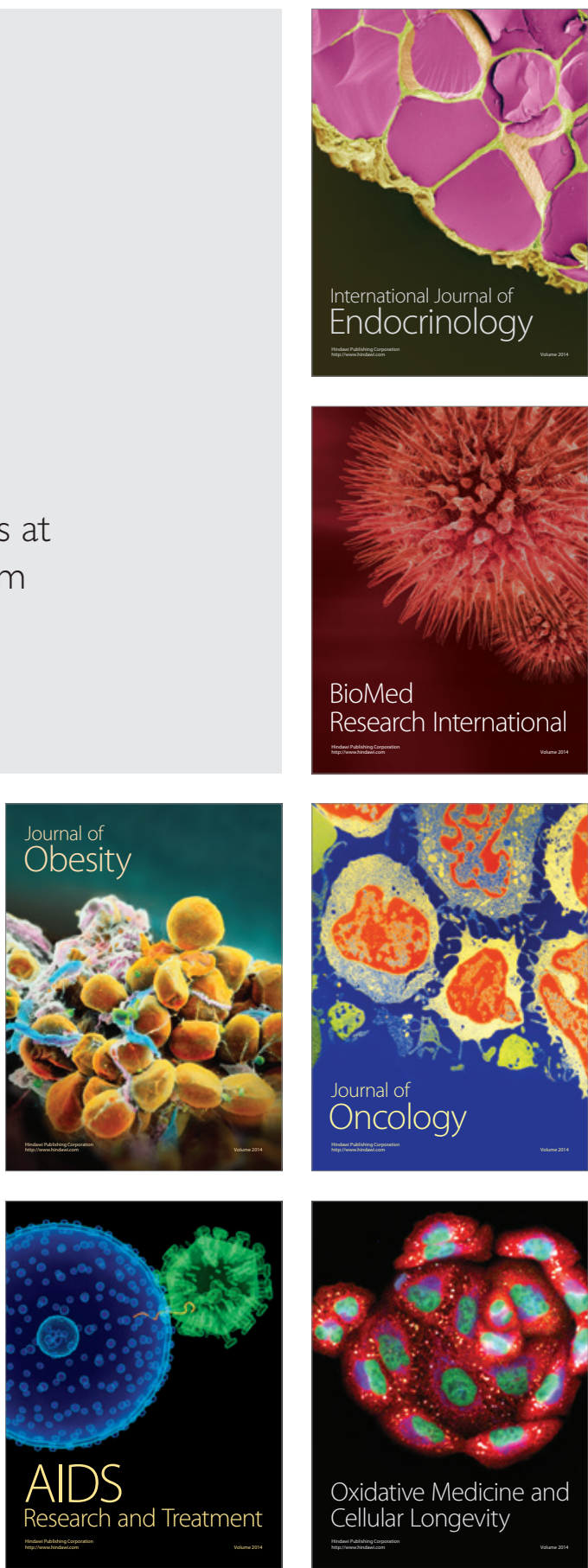